\title{
VISIÓN ESTEREOSCÓPICA Y MEMORIA HISTÓRICA EN UN DÍA EN LA VIDA
}

\author{
Jorge Chen Sham
}

\begin{abstract}
RESUMEN
Un día en la vida nos permite observar cómo el proceso de silenciamiento de los grupos sin voz podría neutralizarse posibilitando que el campesinado salvadoreño tenga acceso a un discurso autorreferido, que escriba y narre su propia experiencia cotidiana y que esta autorrepresentación le permita comprender su devenir histórico en una especie de testimonio caleidoscópico.
\end{abstract}

\begin{abstract}
Un día en la vida shows how the process of silencing voiceless groups can be neutralized, making it possible for the Salvatorian peasantry to have access to a type of discourse that narrates their own everyday experiences. This self-representation, a kaleidoscopic testimony, might help them understand their historical transformation.
\end{abstract}

La producción de Manlio Argueta (n. 1935) se caracteriza por un continuo compromiso con su país, en una región en donde la literatura denuncia los atropellos y la injusticia social. De esta manera, sus inclinaciones políticas lo determinan como un escritor que comulga con los sectores marginados de El Salvador y esto desde su primer texto narrativo El valle de las hamacas (1968). Esta tendencia de denuncia social se prosigue en textos posteriores como Caperucita en la zona roja, con el cual gana el premio Casa de las Américas en 1977 y Un día en la vida, novela que gana también el premio "José Simeón Cañas". En la década de los 80, continúa, con Cuzcatlán donde bate la mar del sur (1986), su labor de conciencia crítica ante una realidad social que demandaba una posición ética de los escritores. Tal responsabilidad histórica coincide, como recuerda Monique Sarfati-Arnaud, con la emergencia de una nueva práctica discursiva que concretara las vivencias y los anhelos de una generación de intelectuales y artistas latinoamericanos y que respondiera a la efervescencia política y al cuestionamiento de los regímenes militares y dictatoriales (Sarfati-Arnaud 1990: 123). Esta nueva práctica discursiva es el testimonio bajo multitud de formas genéricas como podrían ser la autobiografía, la crónica, el relato en verso, la novela o el diario.

Consciente de ello, Manlio Argueta confiesa, en una entrevista con Lorena Argüello aparecida en el Semanario Universidad de la Universidad de Costa Rica a raíz de la publicación de Un día en la vida, que "[n]o se puede escribir de mariposas, mientras que la gente 
muere" (6); lo mismo repite en otra entrevista con Nelly Zulma Martínez, cuando apunta que "la ética va íntimamente vinculada con la estética" (15). De manera que las convicciones políticas de Manlio Argueta afloran sencillamente para concebir una empresa literaria que redinamice la historia salvadoreña (y latinoamericana, por supuesto) bajo una modalidad discursiva que rescata del olvido la voz de los sujetos subalternos y se ofrece como testimonio de ella. No cabe duda de que esta dimensión del "testimonio" mediatiza los textos literarios de Argueta, en lo que han coincidido, por ejemplo, Berverly o Safarti-Arnaud (1990) en relación con la literatura salvadoreña. Sin embargo, mi interés es ensayar otra vía distinta a los textos de Argueta tomando en cuenta la manera como se construye su producción textual. Para ello, este estudio se centrará en Un día en la vida.

Señalaba Juan Carlos Flores, en un artículo del Semanario Universidad de la Universidad de Costa Rica, la importancia no sólo en el cambio de escenario para la narrativa arguetiana por la atención que se le dedica al campo en Un día en la vida, sino también en la técnica sencilla y la transparencia con las que el relato se da al lector (6), con las que se produce una alta carga de efectividad y de identificación, ya que la novela apela a la cotidianeidad campesina y al rescate del espacio familiar y privado en un mundo convulso cuyo escenario es la cruenta guerra civil. Este sabor de lo auténtico se logra, creemos, por el sentido que adquiere la crónica en esta novela, al mismo tiempo sucesión de acontecimientos determinados por la notación de un día y relato de actualidad (Chen 1993). La intencionalidad política de Un día en la vida descansa precisamente en esta contemporaneidad de lo narrado y de la posibilidad de identificación en los lectores; es lo que desea Argueta cuando nos habla del sentido paradigmático de "ese día" en "la vida" de una familia campesina y de sus vecinos, por lo cual la ejemplaridad amplifica lo cotidiano y lo saca de su espacio privado para convertirse en historia de "la vida" salvadoreña y latinoamericana: El problema de El Salvador es un problema latinoamericano, aún con sus más profundas contradicciones,
el sueño del pueblo es el sueño de los latinoamericanos (Blanco 4).

Este trabajo de la realidad contemporánea de El Salvador transforma la denuncia de los maltratos y las injusticias hacia el campesinado en un testimonio colectivo; para ello se vale de un relato en el que se conjugan las voces de Lupe, María Romelia, María Pía y Adolfina, dentro de la sucesión cronológica. La percepción de lo narrado se hace a partir de una pluralidad de narradores que nos transmite en primera persona lo que piensan y hacen. Esta sensación de inmediatez se debe, en efecto, a la relación que se establece entre la historia y el discurso en términos de Tzvetan Todorov (1974). Se trata de una visión desde adentro, por lo cual la distancia se aminora y nos acercamos a la conciencia de los personajes. Por esta razón, Un día en la vida nos sitúa en el terreno de la memoria, haciendo que la conciencia biográfica, la de cada personaje, trascienda hacia la construcción de una memoria histórica, ya que tiene que ver con la autorrepresentación de los sujetos y la imagen que ellos tienen en su devenir.

Siguiendo a Lévy-Strauss, Alfonso González Ortega (1986) analiza cómo Occidente ha creado la ilusión de la Historia como diferencia entre los pueblos "primitivos" y los occidentales, para los cuales la invención de la Historia sirve para situarse en el tiempo y reflexionar sobre sí mismos (25). Así, Occidente no sólo crea la ilusión de lo escrito histórico bajo una perspectiva histórica, sino que los medios y los modos de representación histórica han sido controlados por 
la cultura de élites, lo cual impide su acceso y su autorrepresentación a los grupos menos favorecidos o subalternos (26). Al mismo tiempo, esta cultura hegemónica ha creado silencios o vacíos respecto de acontecimientos o procesos que contravienen las representaciones de la historiografía oficial o que atentan contra la hegemonía y el control de los grupos dominantes. De allí el valor del testimonio que ofrece Un día en la vida en tanto rescate de la memoria histórica del grupo marginado de la historia oficial salvadoreña, el campesinado.

Es aquí donde cobra sentido la crónica hecha por Argueta, porque los sectores marginados y presionados por las estructuras oligárquicas de las sociedades latinoamericanas, representadas en la novela por las voces de "La autoridad" y de un "Ellos", con su fuerte crítica al comunismo y al sector de la Iglesia comprometida con los campesinos, responden con su dinámica ante cualquier proceso de sometimiento y de control. De esta manera, en Un día en la vida, el campesino adquiere conciencia de su pasado y rechaza la versión de la historia oficial de El Salvador (Narváez 1994: 30) y se pronuncia acerca de su pasado y presente. Tal reescritura de la memoria histórica comienza con la interpretación de la revuelta campesina del año 1932, que para el "ellos" (la voz de la guardia en la figura del cabo Martínez), siguiendo así la versión oficial, ha sido expresión del odio hacia la propiedad privada y de la desestabilización al derecho constitucional; por eso:

\footnotetext{
Que el treinta y dos, los comunistas ni siquiera habían triunfado y ya estaban violando a la gente, a los ricos, pues el odio de este pueblo es con los ricos; nacimos con la envidia adentro, no podemos ver ojos contentos en cara ajena porque ya estamos viendo como nos cagamos en el prójimo. Y nosotros estamos precisamente para evitar las envidias, exterminarlas a punta de bala, decisión y firmeza. Estamos preparándonos más y más, porque el comunismo ya viene (119-20).
}

Siguiendo sus palabras, nos damos cuenta de que existe no sólo un desprecio por el campesinado, sino que también se explica la reivindicación de los derechos de los campesinos en términos de una amenaza que hay que acabar, un proceso de lucha contra aquellos enemigos del cristianismo verdadero como si fuera una cruzada o guerra santa. A este enmascaramiento de la historia reciente de El Salvador, se opone Un día en la vida, apropiándose del género de las biografías campesinas marcadas por la oralidad y el rescate de la palabra en sectores marginados. Así, se ofrece la voz a los campesinos que sufren las consecuencias de una guerra civil, el atropello de sus derechos mínimos y la violencia de un poder asimétrico. En este sentido, si como decía Lévy-Strauss, el poder lo detenta quien tenga historia, es decir, quien pueda reflexionar sobre sí mismo y escribir su relato, Un día en la vida nos permite observar cómo el proceso de silenciamiento podría neutralizarse posibilitando que el campesinado salvadoreño tenga acceso a un discurso autorreferido, que éste escriba y narre su propia experiencia cotidiana y que esta autorrepresentación les permita comprender su devenir histórico.

Reconstruir la memoria de los grupos subalternos comienza con la toma de conciencia de su situación hic et nunc y, desde el inicio de la novela, se caracteriza la situación de los campesinos como de pobreza inevitable pero con rasgos de solidaridad comunitaria, como confiesa Lupe al inicio de la novela:

\footnotetext{
Casi todos somos pobres pero no lo tomamos como una desgracia. Ni lo admitimos como algo meritorio. Nunca nos ha importado porque desde hace muchos años, cientos de años, la vida ha pasado igual, sin mayores cambios, todos nos conocemos y nos tratamos de igual a igual, lo mismo vale el que tiene carreta como el que sólo tiene el machete para trabajar (21).
} 
Las palabras de Lupe son interesantísimas; ponderan los valores de la comunidad de bienes y de la igualdad democratizadora propios del discurso evangélico. Al mismo tiempo, subrayan la pertenencia a un grupo y el proceso de opresión bajo el cual los han mantenido sometidos al arbitrio de los grandes terratenientes y a su control ideológico; de ahí el conformismo que expresa su pensamiento, como si la pobreza fuera una mancha y un pecado que embarga a los campesinos.

\footnotetext{
Dicen que somos muchos en este país. Y lo que más abunda son los pobres. Montón de pobres por todos lados. Pero qué le vamos a hacer, qué culpa tenemos. Por eso hay tanta hambre por estos andurriales y por todos lados (50).
}

Sin embargo, el proceso se invierte y el conformismo, aunque haya sido valorado como un valor inherente a su propia condición de grupo, comienza a cuestionarse. Es un atributo de estado y no del ser y, por lo tanto, es relativo y puede ser superado. Esto sucede cuando el campesinado empieza a tomar conciencia de la opresión que ha ejercido la oligarquía y las autoridades por siglos; "cientos de años" como dice Lupe, puestos al descubierto por una Iglesia imbuida por la Teología de la Liberación, aquella para la cual la salvación del hombre es cosustancial a la toma de conciencia de las injusticias sociales. En esta liberación del oprimido, como la denominaría Paulo Freire, la primera toma de conciencia es aquella que ata al hombre a la pobreza endémica y lo impulsa a exigir los derechos mínimos; Lupe nos relata así este proceso de transformación ideológica casi al principio de la novela:

\footnotetext{
Hasta que de pronto, los curas fueron cambiando. Nos fueron metiendo en movimientos cooperativistas, para hacer el bien al otro, a compartir las ganancias. Es una gran cosa hacer el bien a los otros, vivir en paz todos, levantarse antes que el sol para ir a trabajar con los cipotes [...] Ahora todo es en serio en la misa pues los padres comenzaron a abrirnos los ojos y oídos. Uno de ellos nos repetía siempre: para ganarnos el cielo primero luchar por hacer el paraíso en la tierra (24-5).
}

En este sentido, los "nuevos" curas invitan a los campesinos, a los "oprimidos", a abandonar su posición conformista ante la realidad social que los sojuzga. Se trata de una politización de un sector de la Iglesia Católica que defiende una interpretación del mundo desde una perspectiva clasista y propone a los sectores marginales y campesinos un nuevo significado a una fe que los obliga a repensar su existencia en términos de su condición de víctimas del poder político. Con ello, Un día en la vida retoma el proceso de concienciación del campesinado salvadoreño que coincide, en efecto, con la introducción de la Teología de la Liberación en El Salvador y el establecimiento de distintas formas de organización colectiva, las cuales arrastran, en las décadas de los 70 y 80, a una cruenta y dolorosa guerra civil que opondrá a la oligarquía y las fuerzas armadas contra la guerrilla revolucionaria; en medio de ellas quedará el campesinado. Este marco histórico constituye no sólo el entramado ideológico de la novela, sino que también la razón de ser de la subversión que nos propone al reivindicar la memoria histórica, pues la infructuosa revuelta campesina del 32 (Narváez 1994: 30), intento por alcanzar democracia y justicia social, se revierte con la toma de conciencia a la que asistimos ahora. El elemento que sirve de nexo o eslabón entre este acontecimiento y la actualidad de Lupe y demás voces narradoras es también un hecho de sangre, cuyo significado recubre la figura de la víctima indefensa: los asesinatos y desapariciones de los hombres de la familia de Lupe: Chepe, su marido; Justino, su hijo; su yerno, Helio Hernández, y padre de 
Adolfina. De esta manera, la violencia y la muerte recubren a tres generaciones de la familia de Lupe, permitiendo hacer la conexión entre el pasado y el presente, entre los hechos del 32 y la historia privada y familiar.

La amplificación del dolor privado de Lupe y su familia se transforma en ejemplo paradigmático de toma de conciencia de las injusticias y de la situación del oprimido, por lo cual pasamos rápidamente hacia un proceso de develamiento de las carencialidades, en el que sobresale la aparición de un sujeto colectivo, que subsume a Lupe y a las otras voces narradoras en la identificación de su condición actual, su sufrimiento y sus luchas. Se trata de un "nosotros" anafórico que las recubre por igual, del cual proviene su fuerza y su determinación de cambio; son palabras candentes que golpean y remachan la conciencia de Lupe y que pertenecen al recuerdo de su esposo José:

\footnotetext{
Por eso los problemas no tienen solución por la respuesta de una sola persona, sino por la respuesta de todos nosotros, los humildes. Los claros. Esto es muy importante: podés ser humilde y vivir en la oscuridad. La cosa, pues, no consiste en ser o no ser humilde. El problema está en la conciencia de cada uno. La conciencia que tengamos. Entonces la vida se hace como el agua clara de los ríos (118).
}

De manera que van de la mano la concienciación y el proceso de liberación. Así, llama poderosamente la atención la metáfora de la luz, símbolo evangélico del compromiso cristiano y del triunfo de la verdad sobre las fuerzas oscuras de la ignorancia y del mal. En este sentido, el comentario de los editores de La Nueva Biblia Latinoamericana, hecho a "San Juan" Cap. 8, versículos 12-47, señala que Jesús, cuando se proclama como la luz del mundo y como la verdad sobre las que se construye el mundo futuro, está anunciando, al mismo tiempo, la aceptación de su mensaje de redención y la ulterior conversión que le acompaña, ya que mediante la luz el hombre podrá ordenar su existencia atribuyéndole su justo valor:

\footnotetext{
Mediante esa luz, adquiere [el hombre] la capacidad de ordenar su existencia: atribuye a las cosas y a las preocupaciones el lugar y la importancia que les corresponden. También, mediante esta luz, logrará triunfar sobre todo lo oscuro que lleva en sí mismo (La Nueva Biblia Latinoamericana: 197).
}

Por esa razón, la luz se asocia en la novela con el proceso de concienciación, en el sentido de que, como lo afirma la Teología de la Liberación, el oprimido historiza su sufrimiento y encuentra que, a la luz de ese proceso recapitulador de toda escritura autobiográfica (Starobinski 1974: 67-72), su vida adquiere otro sentido. Esto es lo que sucede con el acto de recordar: para Lupe es un trabajo de conciencia lúcida que pone de manifiesto las vivencias y los sucesos reinterpretándolos; de esta manera podrá asumir en sus manos su destino (forjarlo):

\footnotetext{
Pensamos más de la cuenta en la esperanza. Como la luz del candil, es. No podíamos ver en la oscuridad. Despuesito es que José comenzó a decirme: la esperanza mantiene al tonto. Yo nunca le he creído. Entiendo hacia dónde va, pero no le tomo al pie de la letra sus palabras. La esperanza también nos alimenta. No la esperanza del tonto. La otra. La esperanza de uno, cuando se está claro. La conciencia (135-6).
}

Y esto es posible, ya que la interpelación (el llamado desde un punto de vista cristiano) impone la esperanza escatológica del Reino de Justicia y de Hermandad. Esta conciencia en la esperanza posee como presupuesto que las promesas se cumplan aquí en la tierra, en tanto orientación hacia un futuro de justicia y de igualdad para todos: 


\begin{abstract}
La realidad escatológica, en cuanto promesa, sólo puede ser referente si la descubro en la conflictividad de lo contingente, en la lucha social y política, no a partir de cualquier otro punto de vista que sea no-escatológico. Sólo cuando parto desde aquí, puede nacer la esperanza de alcanzar lo "ya realizado" en Cristo. Si no parto desde aquí, la esperanza se convierte en una "espera", inoperante y alienante, de que llegue algún día aquello "ya realizado". El que sólo "espera", y cree poseer en la realidad lo que sólo se posee en la fe, ha perdido toda esperanza. Esa esperanza sólo surge cuando se asume hasta sus últimas consecuencias la realidad conflictiva y difícil del mundo en que se vive (Richard y Torres 1975: 26).
\end{abstract}

De esta manera, para que lo prometido en el mensaje de redención se cumpla, el cristiano debe luchar y comprometerse con forjarse su destino, con lo cual la liberación cristiana responde así a una situación concreta en la que el Evangelio y las palabras de Jesús se reinterpretan en una perspectiva actual y concreta de carácter liberador y salvífico (Boff 1983: 51); esa es la conciencia clara que se amalgama aquí a una espera confiada y certera de una pronta liberación:

\footnotetext{
Pero tenemos que organizarnos. Y por tal razón nos nacen las fuerzas y no nos llenan de miedo. Y si nos da miedo, miedo a quedarnos solos, seguimos de tercos. No nos aburren sus ingratitudes ni sus malcriadezas ni sus asesinatos. Aburrirnos sería como morir. Como darse por vencidos teniendo la razón (165).

Por algunos días se suspenderán las persecuciones en nuestro pueblo y cantones. Y de nuevo volverán [los enemigos]. Ellos vuelven. Pero cada vez nos encontrarán más fuertes para responder. Con todo y las desesperaciones de nuestras madres, hermanas, abuelas, esto que hemos hecho los campesinos nos resucita (147).
}

Se trata de crear un nuevo orden aquí en la tierra, una vida más digna y en defensa de los derechos humanos que choca contra esas fuerzas del mal. Como vimos anteriormente, para el ejército que defiende el poder de la oligarquía, la insurrección de los campesinos se percibe como una revuelta contra el orden y el estado natural de las cosas. La violencia se personaliza en Un día en la vida para que los campesinos vuelvan al antiguo orden; sin embargo, no hay vuelta atrás, ya que la conciencia de "opresión" se transforma en un inconformismo. Desde esta óptica, la novela es la historia de la nueva conciencia adquirida por los oprimidos y la lucha contra los opresores que desean mantener el statu quo: de la pasividad a la acción y a la respuesta franca y beligerante.

Por eso, el texto asume una visión estereoscópica, cuando desaparece el narrador básico y son los personajes quienes cuentan y asumen la narración (Tacca 1981: 64-87). Bajo esta pluralidad de percepciones, todas las narradoras relatan la misma historia de sufrimiento y de persecución, la del campesinado, a manos de los militares empeñados en acabar con la "subversión" popular. Así, el relato de Lupe es el hilo conductor, sus vivencias mediatizadas por la conciencia marcan el ritmo de la cronología (el de las horas) y clarifican lo que narran las otras voces femeninas. Porque ellas serán las que tengan que sobrevivir a la violencia y a la persecución que desata el ejército, tienen la función histórica de velar por la cohesión de sus núcleos familiares en tiempos de guerra. Sin embargo, en la novela otra será la función capital que se les otorga: la de acreditar la verdad de su caso particular o la de ofrecer su propia persona como garantía del juicio emitido (Berrendonner 1981: 63); con ello, todas se transforman en agentes verificadores (61) de la denuncia social que expone Un día en la vida para la validación testimonial: la del cambio posible gracias a la concienciación (poder recordar y analizar su experiencia personal y familiar) de los oprimidos.

De esta manera, Lupe no sólo evoca el pasado de su familia sino que sus recuerdos van invadiendo el terreno de lo histórico cuando interpreta el proceso de concienciación en el que se encuentran los campesinos. Es interesante el paralelismo existente entre el despertar del 
personaje a las cinco de la mañana y la progresiva toma de conciencia de los campesinos, imbricándose magistralmente lo que pertenece al ámbito privado y familiar (el recuerdo de Justino y la desaparición de José) con los sucesos públicos que narran María Romelia (la formación del mitin de San Salvador como protesta por el alza de los insumos agrícolas) o Adolfina (la toma de la Catedral). Cabe destacar, en efecto, que son los personajes masculinos los que sufren en primer lugar la represión y la violencia de las autoridades; llevan la parte más dura del conflicto y están en constante sitio, ya que, por haberse organizado en cooperativas o federaciones, son perseguidos como insurrectos y, para salvar sus vidas, deben huir a las montañas:

Desde que no nos estamos callados y exigimos nuestros derechos la vida se le hace imposible a los hombres de estos lugares. Nacimos pobres y pretenden que sigamos pobres o quisieran terminar con nosotros (164).

La persecución a la que asistimos, con la huida de José al monte, establece el tránsito del caso particular hacia la historia colectiva. Nos trasladamos del espacio de la casa al gran escenario en donde se desarrolla la historia colectiva del campesinado y esto es posible porque para otras voces narradoras como María Pía o Adolfina la lucha contra la explotación y la injusticia es un compromiso moral y social del pueblo salvadoreño:

\footnotetext{
Mi mamá dice que soy demasiado rebelde [habla Adolfina]: pero mi papá siempre me ha dicho que a eso no se le debe llamar rebeldía sino conciencia [...] He ido comprendiendo la vida, el origen de nuestras pobrezas [...] (108-9).
}

Bajo tales condiciones, los sentimientos de solidaridad y de comunidad impregnan la situación comunicativa de Un día en la vida, transformando la historia personal y privada de Lupe y su familia en un discurso testimonio, en el que la memoria de los marginados clama por una reivindicación histórica. Para Renato Prada Oropeza, en el discurso testimonio impera una persona gramatical amplificada, un "nosotros" anafórico que cohesiona por igual todas las experiencias de sufrimiento y de abuso. Así, la rebelión que conduce a las voces narradoras hacia la toma de conciencia tiene como saldo la entrega por una causa y por un compromiso, como lo explicita María Romelia a su mamá: "Si no se trata de pedir por pedir, sino de reclamar nuestro derecho [...] (41), o como lo afirma también Adolfina: "No se preocupe, abuela, algún día vamos a tener nuestro premio y los pobres ya no vamos a sufrir" (55). Conciencia de sus derechos y esperanza en un futuro mejor: he aquí los dos pilares de la autorrepresentación del campesinado en Un día en la vida. La reconstrucción de su pasado histórico pasa precisamente por la toma de conciencia de su marginalidad-explotación, ahí en donde la persecución apela precisamente a la experiencia de las primeras comunidades cristianas, en un texto en el que la memoria y la oralidad confluyen en el discurso testimonial, que responde a la necesidad de documentar y de construir la verdad desde la perspectiva de los que no tienen voz para rescribir la historiografía oficial (Safarti-Anaud 1997: 419). 


\section{Bibliografía}

Acevedo, Ramón Luis. 1994. "La novela centroamericana en la década del ochenta: consolidación e internacionalización”. Exégesis. 7 (19): 2-9.

Argüello, Lorena. 1980. "Manlio Argueta: después de la matemática vino la poesía”. Semanario Universidad, 24 al 30 de octubre: 6.

Argueta, Manlio. 1982. Un día en la vida. San José: EDUCA, $2^{\circ}$ edición.

1986. Cuzcatlán donde bate la mar del sur. Tegucigalpa: Editorial Guaymuras.

Berrendonner, Alain. 1981. Éléments de pragmatique linguistique. París: Éditions de Minuit.

Beverly, John. 1987. “Anatomía del testimonio”. Del Lazarillo al Sandinismo: estudios sobre la función ideológica de la Literatura Española e Hispanoamericana. Minneapolis: The Prisma Institute: 153-68.

La Nueva Biblia Latinoamericana. 1979. Madrid: Ediciones Paulinas-Editorial Verbo Divino, $23^{\circ}$ edición.

Blanco, Patricia. 1983. "Holanda abrió las puertas a Un día en la vida". Semanario Universidad, 19 al 25 de agosto: 4.

Boff, Leonardo. 1983. Jesucristo: El liberador: ensayo de cristología crítica para nuestro tiempo. Santander: Editorial Sal Térrea, $2^{\circ}$ edición.

Carcaud-Macaire, Monique (ed.). 1997. Questionnement des formes-Questionnement du sens: Pour Edmond Cros. Montpellier: Éditions du CERS, tomo I: 413-22.

Cerutti Guldberg, Horacio. 1983. Filosofía de la liberación latinoamericana. México: Fondo de Cultura Económica.

Chen Sham, Jorge. 1993. "La escatología al servicio de la efectividad política en Crónicas romanas de Alfonso Sastre". Revista de Filología y Lingüística de la Universidad de Costa Rica. 19 (1): 25-34.

Flores, Juan Carlos. 1983. "Premian en El Salvador a escritor exiliado". Semanario Universidad, 24 al 30 de octubre: 6.

González Ortega, Alfonso. 1986. Lenguaje cotidiano, represión social y conciencia de la propia historicidad. San José: Instituto de Investigaciones Psicológicas de la Universidad de Costa Rica. 
Narváez, Carlos Raúl. 1994. "Un día en la vida de Manlio Argueta: La ficción ante el espejo de la historia". Exégesis. 7 (19): 28-32.

Prada Oropeza, Renato. 1990. "Constitución y configuración del sujeto en el discurso-testimonio". Casa de las Américas 30 (180): 29-44.

Richard, Pablo y Esteban Torres. 1975. Cristianismo, lucha ideológica y racionalidad socialista. Salamanca: Ediciones Sígueme.

Safarti-Arnaud, Monique. 1990. "Cuzcatlán donde bate la mar del sur: entre la crónica y el mito". Sociocriticism. 6 (1-2): 123-32.

1997. "El discurso testimonial latinoamericano como expresión de una paradoja". En Carcaud-Macaire, Monique (ed.): 413-22.

Starobinski, Jean. 1974. La relación crítica (Psicoanálisis y Literatura). Madrid: Ediciones Taurus.

Tacca, Oscar. 1981. Las voces de la novela. Madrid: Editorial Gredos.

Todorov, Tzvetan. 1974. Literatura y significación. Barcelona: Editorial Planeta, 2 edición.

Zulma Martínez, Nelly. 1985. "Entrevista con Manlio Argueta". Hispamérica. 41: 41-54. 